\title{
MESSAGE FROM THE PRESIDENT
}

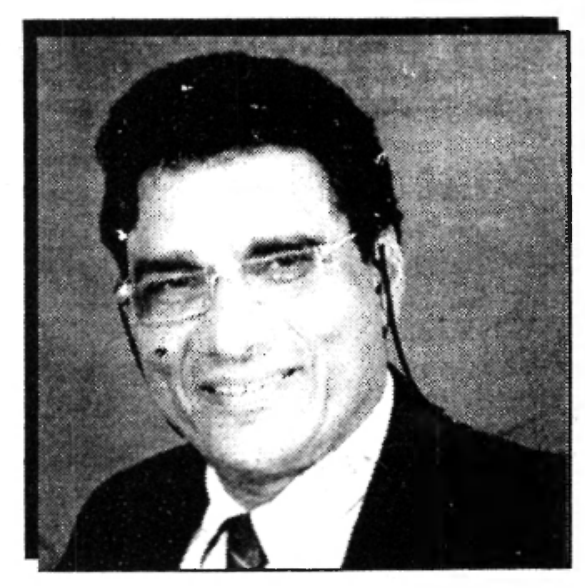

I feel honoured on being elected President of the Indian Institute of Welding for the year 1993. 94. I thank all the members for having reposed faith me and considered me worthy of this prestigious position. I have received numerous congratulatory messages from members. Through the medium of the Indian Welding Journal, I express my heartfelt gratitude to them.

The Indian Institute of Welding has been going through a difficult period for some time now . I have devoted considerable amount of time studying the problem and have deliberated on the options available to your Council in my Key-note address delivered at the inaugural function of the recently concluded National Welding Seminar at Bhilai. This address is published in this issue of the Journal. The main thrust in my initial period of tenure, will be to streamline the functioning of the headoffice (HO) and open communication channels between different Branches and HO. It will be my endeavour to visit each IIW Branch atleast once while I am in office and meet the Executive Committee if not all the members. I may not be able to plan special visit but during my official tours if I happen to visit a place where there is an IIW Branch I would make it a point to meet our members. However, in case you have any grievance and/or suggestion to improve the working of our Institute, I would urge you to write to me directly. I can assure you that your communications will receive my immediate attention. I am sure, with your co-operation and support your Council will succeed in surmounting the difficulties facing the Indian Institute of Welding. On behalf of the National Council I wish you all a Happy New Year.

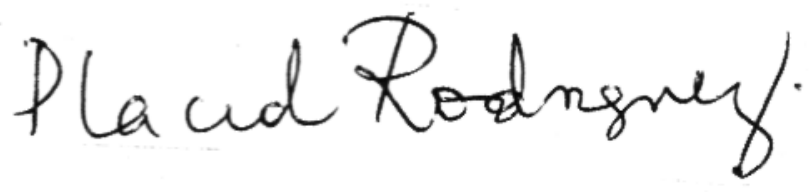

Placid Rodriguez 


\title{
Dr. PLACID RODR'IGUEZ
}

Date of Birth : October 5, 1940

Educational Qualifications:

B.Sc. (1958, Kerala)

B.E. $(1960$, IISC)

M.S. (1965, Tennessee)

Ph. D. (1976, IISc)

\section{Membership of Professional Bodies :}

\author{
Fellow, Indian National Acedemy of Engineers \\ Fellow, Indian Academy of Science \\ Fellow, Indian Institute of Welding \\ Fellow, Indian Institute of Metals \\ Hony.Fellow, Indian Society for Non-Destructive Testing \\ Fellow, Society for Advancement of Electrochemical Science and Technology
}

Dr. Placid Rodriguez, a Metallurgical of International repute, is known for his significant contribution in the fields of welding science and mechanical metallurgy of nuclear materials, He started his career in BARC, Bombay in 1990. He spent two years (1963-1965) as a Visiting Scientist, at the Oak Ridge National Laboratory, USA and three months in 1974 with Technicatome, France. Since 1974 he has been with the Indira Gandhi Centre for Atomic Research where he has established a comprehensive programme on special steels and alloys for Fast Breeder Reactors with particular emphasis on the scientific basis of welding, Metal Fabrication and NDT. On December 1, 1992, Dr., Rodriguez was appointed Director, IGCAR, Kalpakkam.

In the basic research area, his major contributions have been in studies on Dislocation Dynamics and Dynamic Strain Ageing (DSA) and in understanding the damage caused by creep, fatigue, environment and DSA, and the interactions and synergism between the different damage mechanisms in weld and base metals. He has also contributed significantly in advancing the understanding of microstructural instability of welds during elevated temperature service. These studies have contributed to the evaluation of the methodology for assesment, prediction and extension of the life of engineering components and plants. Through his guidance and encouragement, IGCAR has been in the forefront of welding research at the National Scene and is now recognised internationally as one of the Centres of excellence in this area.

Dr. Rodriguez is the Chairman of Working Group in Welding Research of DST. He is also the Indian Coordinator for the Indo-US joint collaborative research programme in welding science. He is the Chief Editor of the Transactions of the Indian Institute of Metals and a member of the Editotial Advisory Board of Steel India, Metals, Materials and Processes and International Journal of Pressure Vessels and Piping.

He is a recipient of several awards, including the National Metallurgists' Day Award (1978), the Keith Hartley Memorial Lecture Medal (1986), the G.D.Birla Gold Medal (1987), Vasvik Research Award (1990) and the MRSI Lecture Medal (1991)

Dr. Rodriguez has been elected President of the Indian Institute of Welding (1993-94), and Vice President of the Indian Institute of Metals (1992-95). 